\title{
Double condensation of singularities for product-quadrature formulas with differentiable functions
}

\section{AlEXANDRU I. MitREA}

\section{ABSTRACT.}

The main goal of this paper is to emphasize the phenomenon of double condensation of singularities for spaces of differentiable functions with respect to product-quadrature formulas associated to a class of node triangular matrices in $[-1,1]$, including a Gegenbauer node matrix and the matrix of equidistant nodes in $[-1,1]$.

Department of MATHEMATics

TECHNICAL UNIVERSITY OF CLUJ-NAPOCA

MEMORANDUMUlui 28, 400114 CluJ-NAPOCA, RomANiA

E-mail address: alexandru.ioan.mitrea@math.utcluj.ro 